\title{
Trends in Care Practices, Morbidity, and Mortality of Extremely Preterm Neonates, 1993-2012
}

\section{Barbara J. Stoll, MD ${ }^{1}$, Nellie I. Hansen, MPH${ }^{2}$, Edward F. Bell, MD ${ }^{3}$, Michele C. Walsh, MD MS $^{4}$, Waldemar A. Carlo, MD ${ }^{5}$, Seetha Shankaran, MD ${ }^{6}$, Abbot R. Laptook, MD ${ }^{7}$, Pablo J. Sánchez, MD $^{8}$, Krisa P. Van Meurs, MD $^{9}$, Myra Wyckoff, MD ${ }^{10}$, Abhik Das, PhD ${ }^{11}$, Ellen C. Hale, RN BS CCRC ${ }^{1}$, M. Bethany Ball, BS CCRC ${ }^{9}$, Nancy S. Newman, BA RN ${ }^{4}$, Kurt Schibler, MD ${ }^{12}$, Brenda B. Poindexter, MD MS ${ }^{13}$, Kathleen A. Kennedy, MD MPH ${ }^{14}$, C. Michael Cotten, MD MHS ${ }^{15}$, Kristi L. Watterberg, MD ${ }^{16}$, Carl T. D'Angio, MD ${ }^{17}$, Sara B. DeMauro, MD MSCE ${ }^{18}$, William E. Truog, MD ${ }^{19}$, Uday Devaskar, MD ${ }^{20}$, and Rosemary D. Higgins, MD ${ }^{21}$ for the Eunice Kennedy Shriver National Institute of Child Health and Human Development Neonatal Research Network \\ ${ }^{1}$ Emory University School of Medicine, Department of Pediatrics, Children's Healthcare of Atlanta, Atlanta, GA \\ ${ }^{2}$ Social, Statistical and Environmental Sciences Unit, RTI International, Research Triangle Park, NC}

${ }^{3}$ Department of Pediatrics, University of lowa, lowa City, IA

${ }^{4}$ Department of Pediatrics, Rainbow Babies \& Children's Hospital, Case Western Reserve University, Cleveland, $\mathrm{OH}$

${ }^{5}$ Division of Neonatology, University of Alabama at Birmingham, Birmingham, AL

${ }^{6}$ Department of Pediatrics, Wayne State University, Detroit, MI

${ }^{7}$ Department of Pediatrics, Women \& Infants Hospital, Brown University, Providence, RI

${ }^{8}$ Department of Pediatrics, Center for Perinatal Research, Nationwide Children's Hospital, The Ohio State University, Columbus, $\mathrm{OH}$

${ }^{9}$ Department of Pediatrics, Division of Neonatal and Developmental Medicine, Stanford University School of Medicine and Lucile Packard Children's Hospital, Palo Alto, CA

${ }^{10}$ Department of Pediatrics, University of Texas Southwestern Medical Center, Dallas, TX

${ }^{11}$ Social, Statistical and Environmental Sciences Unit, RTI International, Rockville, MD

${ }^{12}$ Perinatal Institute, Cincinnati Children's Hospital Medical Center, Cincinnati, $\mathrm{OH}$

${ }^{13}$ Department of Pediatrics, Indiana University School of Medicine, Indianapolis, IN

${ }^{14}$ Department of Pediatrics, University of Texas Medical School at Houston, Houston, TX

${ }^{15}$ Department of Pediatrics, Duke University, Durham, NC

${ }^{16}$ University of New Mexico Health Sciences Center, Albuquerque, NM

${ }^{17}$ University of Rochester School of Medicine and Dentistry, Rochester, NY 
Alpert Medical School of Brown University and Women \& Infants Hospital of Rhode Island (U10 HD27904) - Martin Keszler, MD; William Oh, MD; Angelita M. Hensman, MS RNC-NIC BSN; Kristen Angela, RN; Kristin Basso, RN MaT.

Brigham and Women's Hospital, Harvard Medical School (U10 HD34167) - Ann R. Stark, MD; Kerri Fournier, RN.

Stolfase Western Reserve University, Rainbow Babies \& Children's Hospital (U10 HD21364, M01 RR80) - Anna Marie Hibbs, MPåge 2 Avroy A. Fanaroff, MD.

Children's Mercy Hospital (U10 HD68284) - Eugenia K. Pallotto, MD MSCE; Howard W. Kilbride MD; Cheri Gauldin, RN BS

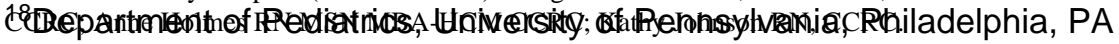

Cincinnati Children's Hospital Medical Center, University of Cincinnati Medical Center, and Good Samaritan Hospital (U10 HD27853, M01 RR8084, UL1 TR77) - Suhas G. Kallapur, MD; Edward F. Donovan, MD; Cathy Grisby, BSN CCRC; Barbara Alexander, RN; Kate Bridges, MD; Jody Hessling, RN; Holly L. Mincey, RN BSN; Marcia Worley Mersmann, RN CCRC. Duke University School of Medicine, University Hospital, University of North Carolina, and Duke Regional Hospital (U10 HD40492, UL1 TR1117, M01 RR30, UL1 TR1111) - Ronald N. Goldberg, MD; Joanne Finkle, RN JD; Kimberley A. Fisher, PhD FNP-BC IBCLC; Kathy J. Auten, MSHS; Katherine A. Foy, RN; Melody B. Lohmeyer, RN MSN; Gloria Siaw, BSN CRA; Matthew M. Laughon, MD MPH; Carl L. Bose, MD; Janice Bernhardt, MS RN; Gennie Bose, RN.

Emory University, Children's Healthcare of Atlanta, Grady Memorial Hospital, and Emory University Hospital Midtown (U10 HD27851, M01 RR39, UL1 TR454) - David P. Carlton, MD; Ravi M. Patel, MD; Yvonne Loggins, RN; Ellen Hale, RN.

Eunice Kennedy Shriver National Institute of Child Health and Human Development - Linda L. Wright, MD; Stephanie Wilson Archer, MA.

Indiana University, University Hospital, Methodist Hospital, Riley Hospital for Children at Indiana University Health, and Eskenazi Health (U10 HD27856, M01 RR750, UL1 TR6) - Greg Sokol, MD; James A. Lemons, MD; Leslie Dawn Wilson, BSN CCRC; Diana D. Appel, RN BSN; Faithe Hamer, BS; Dianne E. Herron, RN; Lucy C. Miller, RN BSN CCRC.

Nationwide Children's Hospital and The Ohio State University Medical Center (U10 HD68278) - Leif D. Nelin, MD; Sudarshan R. Jadcherla, MD; Patricia Luzader, RN; Christine A. Fortney, PhD RN; Bronte Clifford, BA; Melanie Stein, BBA, RRT; Erin Wishloff, RRT; Amanda Daubenmire, BS; Karen Leonhart, BS; Julie Gutentag, RN, BSN; Tiffany Sharp, CMOA; Courtney Cira, BS, RRT, MBA; Lina Yousef, MD; Pamela Moorehead, BS; Rox Ann Sullivan, RN, BSN.

RTI International (U10 HD36790) - Dennis Wallace, PhD; Kristin M. Zaterka-Baxter, RN BSN CCRP; Margaret M. Crawford, BS CCRP; Jenna Gabrio, BS CCRP; Betty K. Hastings; Elizabeth M. McClure, MEd; Jeanette O'Donnell Auman, BS; Carolyn M. Petrie Huitema, MS CCRP; W. Kenneth Poole, PhD.

Stanford University and Lucile Packard Children's Hospital (U10 HD27880, M01 RR70, UL1 TR93) - David K. Stevenson, MD; Marian M. Adams, MD; Andrew W. Palmquist, RN BSN; Melinda S. Proud, RCP.

Tufts Medical Center, Floating Hospital for Children (U10 HD53119, M01 RR54) - Ivan D. Frantz III, MD; Brenda L. MacKinnon, RNC; Ellen Nylen, RN BSN.

University of Alabama at Birmingham Health System and Children's Hospital of Alabama (U10 HD34216, M01 RR32) Namasivayam Ambalavanan, MD; Monica V. Collins, RN BSN MaEd; Shirley S. Cosby, RN BSN.

University of California - Los Angeles, Mattel Children's Hospital, Santa Monica Hospital, Los Robles Hospital and Medical Center, and Olive View Medical Center (U10 HD68270) - Meena Garg, MD; Teresa Chanlaw, MPH; Rachel Geller, RN BSN.

University of California - San Diego Medical Center and Sharp Mary Birch Hospital for Women (U10 HD40461) - Neil D. Finer, MD; Maynard R. Rasmussen, MD; Paul R. Wozniak, MD; Wade Rich, BSHS RRT; Kathy Arnell, RNC; Clarence Demetrio, RN; Christopher Henderson, AS CRTT.

University of Iowa and Mercy Medical Center (U10 HD53109, M01 RR59, UL1 TR442) - Tarah T. Colaizy, MD MPH; John A. Widness, MD; Dan L. Ellsbury, MD; Karen J. Johnson, RN BSN; Donia B. Campbell, RNC-NIC.

University of Miami, Holtz Children's Hospital (U10 HD21397, M01 RR16587) - Shahnaz Duara, MD; Ruth Everett-Thomas, RN MSN.

University of New Mexico Health Sciences Center (U10 HD53089, U10 HD27881, M01 RR997, UL1 TR41) - Robin K. Ohls, MD;

Conra Backstrom Lacy, RN.

University of Pennsylvania, Hospital of the University of Pennsylvania, Pennsylvania Hospital, and Children's Hospital of

Philadelphia (U10 HD68244) - Barbara Schmidt, MD MSc; Haresh Kirpalani, MB MSc; Aasma S. Chaudhary, BS RRT; Toni

Mancini, RN BSN CCRC; Dara M. Cucinotta, RN.

University of Rochester Medical Center, Golisano Children's Hospital, and the University of Buffalo Women's and Children's Hospital of Buffalo (U10 HD68263, U10 HD40521, M01 RR44, UL1 TR42) - Dale L. Phelps, MD; Ronnie Guillet, MD PhD; Satyan Lakshminrusimha, MD; Linda J. Reubens, RN CCRC; Holly I.M. Wadkins; Michael G. Sacilowski, BS; Erica Burnell,RN; Ashley Williams, MSEd.

University of Tennessee Health Science Center (U10 HD21415) - Sheldon B. Korones, MD; Tina Hudson, RN BSN.

University of Texas Southwestern Medical Center at Dallas, Parkland Health \& Hospital System, and Children's Medical Center Dallas (U10 HD40689, M01 RR633) - Luc P. Brion, MD; Charles R. Rosenfeld, MD; Walid A. Salhab, MD; Diana M. Vasil, RNCNIC; Alicia Guzman; Gaynelle Hensley, RN; Melissa H. Leps, RN; Nancy A. Miller, RN.

University of Texas Health Science Center at Houston Medical School, Children's Memorial Hermann Hospital, and Lyndon Baines Johnson General Hospital/Harris County Hospital District (U10 HD21373) - Jon E. Tyson, MD MPH; Georgia E. McDavid, RN;

Esther G. Akpa, RN BSN; Beverly Foley Harris, RN BSN; Claudia I. Franco, RNC MSN; Anna E. Lis, RN BSN; Sara C. Martin, RN BSN; Patricia Ann Orekoya, RN BSN; Patti L. Pierce Tate, RCP; Maegan C. Simmons, RN.

University of Utah Medical Center, Intermountain Medical Center, LDS Hospital, and Primary Children's Medical Center (U10 HD53124, M01 RR64, UL1 TR105) - Roger G. Faix, MD; Bradley A. Yoder, MD; Karen A. Osborne, RN BSN CCRC; Jennifer J. Jensen, RN BSN; Cynthia Spencer, RNC; Kimberlee Weaver-Lewis, RN BSN.

Wake Forest Baptist Medical Center, Brenner Children's Hospital, and Forsyth Medical Center (U10 HD40498, M01 RR7122) - T. Michael O’Shea, MD MPH; Robert G. Dillard, MD; Nancy J. Peters, RN CCRP.

Wayne State University, University of Michigan, Hutzel Women's Hospital, and Children's Hospital of Michigan (U10 HD21385) Beena G. Sood, MD MS; Athina Pappas, MD; John Barks, MD; Rebecca Bara, RN BSN; Maria Batts, RRT; Elizabeth Billian, RN MBA; Shelley Hendel, AD; Kimberly Hayes-Hart, RN MSN NNP-BC; Mary E. Johnson, RN BSN; Geraldine Muran, RN BSN; Carolyn Rosman, RN; Kara Sawaya, RN BSN; Laura Sumner, RN BSN; Mary Christensen, RT; Stephanie A. Wiggins, MS. Yale University, Yale-New Haven Children's Hospital (U10 HD27871, M01 RR6022, UL1 TR142) - Richard A. Ehrenkranz, MD; Monica Konstantino, RN BSN; Matthew Bizzarro, MD; Patricia Gettner, RN; JoAnn Poulsen, RN; Janet Taft, RN BSN; Joanne Williams, RN BSN. 
${ }^{19}$ Department of Pediatrics, Children's Mercy Hospital, Kansas City, MO

${ }^{20}$ Department of Pediatrics, University of California, Los Angeles, CA

${ }^{21}$ Eunice Kennedy Shriver National Institute of Child Health and Human Development, National Institutes of Health, Bethesda, MD

\section{Abstract}

Importance—Extremely preterm infants contribute disproportionately to neonatal morbidity and mortality.

Objective-To review 20-year trends in maternal/neonatal care, complications, and mortality among extremely preterm infants born at Neonatal Research Network centers.

Design, Setting, Participants-Prospective registry of 34,636 infants 22-28 weeks' gestational age (GA) and 401-1500 gram birthweight born at 26 Network centers, 1993-2012.

Exposure-Extremely preterm birth.

Main Outcomes-Maternal/neonatal care, morbidities, and survival. Major morbidities, reported for infants who survived more than 12 hours, were: severe necrotizing enterocolitis, infection, bronchopulmonary dysplasia, severe intracranial hemorrhage, cystic periventricular leukomalacia, and/or severe retinopathy of prematurity. Regression models assessed yearly changes, adjusting for study center, race/ethnicity, GA, birthweight for GA, and sex.

Results-Use of antenatal corticosteroids increased from 1993 to 2012 (348/1431 [24\%] to $1674 / 1919$ [87\%], $\mathrm{p}<0.001$ ), as did cesarean delivery (625/1431 [44\%] to 1227/1921 [64\%], $\mathrm{p}<0.001)$. Delivery room intubation decreased from 1144/1433 (80\%) in 1993 to $1253 / 1922(65 \%)$ in 2012 ( $\mathrm{p}<0.001)$. After increasing in the 1990s, postnatal steroid use declined to $141 / 1757(8 \%)$ in 2004 ( $\mathrm{p}<0.001$ ), with no significant change thereafter. Although most infants were ventilated, continuous positive airway pressure without ventilation increased from 120/1666 (7\%) in 2002 to 190/1756 (11\%) in 2012 ( $\mathrm{p}<0.001$ ). Despite no improvement from 1993 to 2004, rates of lateonset sepsis declined between 2005 and 2012 for infants of each GA (median GA 26 weeks, 109/296 [37\%] to 85/320 [27\%], adjusted relative risk [aRR]: 0.93 [95\% CI, 0.92-0.94]). Rates of other morbidities declined, but bronchopulmonary dysplasia increased between 2009 and 2012 for infants 26-27 weeks (26 weeks, 130/258 [50\%] to 164/297 [55\%], p<0.001). Survival increased between 2009 and 2012 for infants 23 weeks (41/152 [27\%] to 50/150 [33\%], aRR: 1.09 [95\% CI, $1.05-1.14$ ]) and 24 weeks (156/248 [63\%] to 174/269 [65\%], aRR: 1.05 [95\% CI, 1.03-1.07]), with smaller relative increases for infants 25 and 27 weeks and no change for infants 22,26 and 28 weeks. Survival without major morbidity increased approximately $2 \%$ per year for infants $25-28$ weeks with no change for infants 22-24 weeks.

Conclusions and Relevance-Among extremely preterm infants born at US academic centers over the last 20 years, changes in maternal and infant care practices and modest reductions in several morbidities were observed, although bronchopulmonary dysplasia increased. Survival increased most markedly for infants born at 23 and 24 weeks and survival without major morbidity increased for infants 25-28 weeks. These findings may be valuable in counselling families and developing novel interventions. 


\section{Introduction}

Advances in medicine over the past 2 decades have changed care for mothers in preterm labor and for extremely preterm infants. Slow but steady improvements in outcomes have been reported, with substantial differences across centers. ${ }^{1-7}$ Nonetheless, extremely preterm infants continue to contribute disproportionately to the burden of neonatal morbidity, mortality, and long-term neurodevelopmental disability. ${ }^{8,9}$ Evaluation of current in-hospital morbidity and mortality data among these smallest and most vulnerable infants is important in counseling families and considering novel interventions to improve outcome.

Since 1987, the Eunice Kennedy Shriver National Institute of Child Health and Human Development Neonatal Research Network (NRN) has monitored outcomes and trends in antenatal and postnatal care, morbidities, and mortality among extremely preterm infants born at academic centers of the NRN. ${ }^{10}$ The last overview evaluated data from 2003 through 2007. ${ }^{2}$ As there have been considerable changes in obstetric and neonatal care over the past 2 decades, this study comprehensively reviews interventions and outcomes of infants 22-28 weeks gestational age (GA) born at NRN hospitals between 1993 and 2012.

\section{Methods}

This study evaluated infants born at NRN hospitals between 1993 and 2012, with GA 22 0/7 through 28 6/7 weeks and birthweight (BW) 401-1500 grams. NRN centers are selected by peer review and represent academic institutions with large obstetric and neonatal services, expertise in caring for high-risk mothers and extremely preterm infants, and experience in multicenter clinical research. Study sites are distributed throughout the United States. All delivery hospitals at NRN sites are included in the registry and represent almost $5 \%$ of all extremely preterm births in the United States.

From 1993-2007, all very-low-birthweight infants (401-1500 grams) born at or admitted to study centers within 14 days of birth were included in the registry. Eligibility criteria changed in 2008 to include inborn infants with BW 401-1000 grams or GA 22-28 weeks. Our study population of infants 22-28 weeks GA was restricted to inborn infants with BW 401-1500 grams, to maintain consistency over the entire study period.

Data were collected prospectively with maternal pregnancy and delivery information collected soon after birth, and infant data collected until death, hospital discharge/transfer, or 120 days of age. Infants who died in the first 12 hours of life were included in analyses of overall mortality but were excluded from analyses focused on morbidities and respiratory support as these outcomes were not collected for infants who died within 12 hours. Morbidities diagnosed during the initial hospital stay ${ }^{1,2,10,11-15}$ were recorded for infants who survived more than 12 hours. Definitions were used consistently over the study period. Detailed respiratory support data were collected beginning 2002.

This study was approved by the institutional review board at each site, with waiver of consent granted at most study sites and written or oral parental consent required by 3 sites. 


\section{Outcomes}

We focused on changes over time in maternal and neonatal care practices and neonatal morbidity and mortality. Changes in maternal/neonatal characteristics, including maternal age, race/ethnicity (based on chart abstraction using categories specified in the study manual of operations), prenatal care, insulin-dependent diabetes, hypertension; multiple birth; birth defects; infant GA, BW, and small for GA were examined to assess changes over time that might influence outcomes. Care practices reported were chosen because they have been associated with neonatal outcomes and included antenatal steroids, antenatal antibiotics, cesarean delivery, delivery room resuscitation, surfactant therapy, postnatal steroids, and respiratory support. Morbidities included necrotizing enterocolitis, stage 2-3 (NEC) ${ }^{16,17}$; early ( $\leq 72$ hours) and late-onset ( $>72$ hours) sepsis, defined by cultures positive for bacteria or fungi, and antibiotic therapy $\geq 5$ days or intent to treat but death $<5$ days ${ }^{18,19}$; intracranial hemorrhage (ICH); cystic periventricular leukomalacia (PVL); retinopathy of prematurity (ROP) among infants hospitalized at 28 days; and bronchopulmonary dysplasia (BPD), defined as oxygen use at 36 weeks postmenstrual age or at discharge/transfer if before 36 weeks in infants who survived to 36 weeks. ICH was based on the most severe cranial sonogram prior to hospital discharge, transfer, or death. Grade 3/4 ICH was considered severe. ${ }^{20}$ Survival to discharge and survival without major morbidity (NEC, severe ICH, PVL, early or late-onset sepsis or meningitis, BPD or ROP $₫$ tage 3) were studied.

\section{Statistical Analysis}

Descriptive statistics are shown in four 5-year periods (1993-1997, 1998-2002, 2003-2007, 2008-2012) and for the first and last years of the study (1993, 2012), and yearly changes are shown in figures. Analyses examined yearly changes over time, with birth year treated as a continuous variable. Changes in maternal/neonatal characteristics were assessed using linear or logistic models. Linear trends in outcomes were assessed using Poisson regression models with robust variance estimators ${ }^{21}$ to estimate relative risks (RRs) and $95 \%$ confidence intervals (CIs) for the change per year while adjusting for covariates. Models included covariates for birth year, study center, maternal race/ethnicity, infant GA, SGA, and sex, with exceptions noted in table footnotes. P-values for tests of trends were determined by Score or Wald chi-square or F tests. Analyses were based on infants with non-missing values of covariates and outcomes. Less than $1 \%$ of observations were missing values of covariates or outcomes except that approximately $5 \%$ of infants could not be evaluated for major morbidity and $4 \%$ of infants surviving to 36 weeks postmenstrual age were not evaluated for BPD. Missing values were not imputed with the exception that missing ethnicity for white $(0.4 \%)$ and black $(2 \%)$ race was considered to be non-Hispanic.

Graphs of the percent of infants with each outcome by birth year were examined to suggest the modeling strategy with respect to year. Each graph included a local regression (LOESS) curve that was fit using the data proportions and a smoothing parameter $(0.3$ or 0.4$)$ for assessment of trend. Trends generally consistent over the period were assessed by including year in the models as a single continuous variable. For trends that varied over the period, linear splines with knot points (changes in trend) suggested by the graph were used to assess variation. Where one RR is reported for an outcome, the change per year was estimated for 1993-2012. Where more than one RR is reported, the change per year was estimated for the 
periods shown to capture variation in trend over time. Yearly trends in outcomes were assessed overall and for infants of each GA through use of interaction terms between each level of GA and year effects. For outcomes with non-significant year-GA interactions, adjusted RRs from main effects models are reported. For outcomes with significant year-GA interactions, adjusted RRs from models that included the interaction are reported for infants of each GA, with graphs shown by GA in Supplemental Figures.

The primary analyses used data from all centers. Analyses were repeated using data from the centers in the NRN all 20 years. Except as noted, results were similar to those from the primary analyses and are not reported. A 2 -sided p-value $<0.05$ was considered significant. Analyses were completed using SAS statistical software version 9.3 (SAS Institute).

\section{Results}

During 1993-2012, 34,636 infants 22-28 weeks GA and 401-1500 grams BW were born at 26 NRN centers. Eight centers participated all 20 years (18,236 infants, 53\%), 5 for 14-19 years (26\%), 1 for 12 years (4\%), 7 for 6-9 years (14\%), 1 for 4 years (2\%), and 4 for 2 years (2\%). Maternal age increased from a mean (SD) of 25.7 (6.5) years in 1993 to 27.8 (6.3) years in 2012, p $<0.001$ (Table 1). Race/ethnicity changed, with smaller percentages of non-Hispanic black mothers (55\% in 1993 to 39\% in 2012) and higher percentages of nonHispanic white and Hispanic mothers ( $31 \%$ to $42 \%$ and $12 \%$ to $14 \%$, respectively, $\mathrm{p}<0.001$ ). Maternal hypertension increased from 12\% in 1993 to $27 \%$ in 2012 ( $\mathrm{p}<0.001)$ and maternal insulin-dependent diabetes from $2 \%$ to $5 \%(\mathrm{p}<0.001)$.

A major birth defect was reported for 1292 infants (3.7\%) and the proportion did not change significantly between 1993 and 2012, $\mathrm{p}=0.25$. The percent of infants from a multiple birth increased from $18 \%$ in 1993 to $27 \%$ in 1998 ( $\mathrm{p}<0.001$ ), with no further increase noted. Study participants were $52 \%$ male, with similar proportions in each year.

\section{Care practices}

Use of antenatal corticosteroids increased from 1993 to 1996 (348/1431 [24\%] to 1049/1413 [74\%], $\mathrm{p}<0.001$; Figure 1). The change varied significantly by GA, with larger relative increases each year among mothers of lower GA infants (22 weeks, 2/79 [3\%] to 17/70 [24\%], adjusted RR (aRR) [95\% CI] for change per year: 1.81 [1.38-2.38]; 28 weeks, 93/310 [30\%] to 252/295 [85\%], aRR: 1.30 [1.26-1.35]; eFigure 1). After 1996, use increased more slowly; by 2012, 1674/1919 (87\%) mothers received at least one dose of corticosteroids (eTable 1). Antenatal antibiotic use increased during the early 1990s from 631/1431 (44\%) in 1993 to 1310/1729 (76\%) in 1997 (p<0.001; Figure 1, eTable 1). After 1997 , antenatal antibiotic use decreased to $1191 / 1889(63 \%)$ in $2006(\mathrm{p}<0.001)$ but rose to $1401 / 1916(73 \%)$ in $2012(\mathrm{p}<0.001)$. In the 8 centers in the NRN all 20 years, no increase was noted after 2006.

Cesarean section deliveries increased, most markedly from 1993 to 2005 (625/1431 [44\%] to $1247 / 2024$ [62\%], p<0.001; Figure 1). The increase differed by GA, with larger relative yearly increases among infants of lower GA (eFigure 2, eTable 1). Cesarean deliveries continued to increase slightly after 2005 for infants born at 26 and 27 weeks. 
Delivery room tracheal intubation, resuscitation drugs, and chest compression decreased over time, while surfactant use increased (Figure 1, eTable 1). In 1993, 1144/1433 (80\%) infants were intubated in the delivery room compared with 1253/1922 (65\%) in 2012; decreases differed by GA (eFigure 3). Surfactant was given to $861 / 1433(60 \%)$ infants in 1993 and 1501/1913 (78\%) in 2003, with increases in all GAs except infants born at 22 weeks (eFigure 4). After 2003, surfactant use decreased slightly among infants born at 2728 weeks.

Among infants who survived more than 12 hours, postnatal corticosteroid use increased significantly in the early 1990s, from 356/1240 (29\%) in 1993 to 508/1230 (41\%) in 1996 (aRR: 1.18 [1.14-1.21], $\mathrm{p}<0.001$; Figure 1). Postnatal steroid use decreased to a low of $141 / 1757(8 \%)$ in $2004, \mathrm{p}<0.001$, with no significant change thereafter.

\section{Respiratory support (2002-2012)}

Most infants who survived more than 12 hours were mechanically ventilated (Table 2). In $2002,1497 / 1666$ (90\%) infants received conventional ventilation. Conventional ventilation decreased to $1442 / 1756(82 \%)$ in 2012 ; changes per year varied by GA (eTable 2). High frequency ventilation increased from 504/1666 (30\%) in 2002 to 646/1569 (41\%) in 2007 (aRR: 1.03 [1.01-1.04], p<0.001), with no significant change 2008-2012. The percent never ventilated decreased for infants born at 22-23 weeks, but increased for infants born at 24 and 26-28 weeks (26 weeks, 20/328 [6\%] in 2002 to 29/326 [9\%] in 2012, aRR: 1.06 [1.021.10], $\mathrm{p}=0.002$; 28 weeks, $81 / 380$ [21\%] to 128/423 [30\%], aRR: 1.05 [1.03-1.07], p<0.001; eTable 2). Nasal synchronized intermittent mandatory ventilation (SIMV) increased from $239 / 1666(14 \%)$ in 2002 to $657 / 1755$ (37\%) in 2012, p<0.001 (Table 2). Nasal SIMV was the highest level of support for $13 / 1666(<1 \%)$ infants in 2002 but increased to $45 / 1756$ $(3 \%)$ in 2012, $\mathrm{p}<0.001$. Use of CPAP without ventilation increased from 120/1666 (7\%) in 2002 to 190/1756 (11\%) in 2012 (aRR: 1.05 [1.03-1.07], p<0.001; eTable 2). Few infants born before 25 weeks received nasal SIMV or CPAP without first receiving mechanical ventilation.

\section{Morbidities}

Overall, 689/30789 (2\%) infants had early-onset sepsis, with no significant change over the period (eTable 3). In 1993, 89/1240 (7\%) infants were diagnosed with NEC, increasing to $187 / 1496(13 \%)$ in $2008(\mathrm{p}<0.001)$ before falling to $161 / 1756(9 \%)$ by $2012(\mathrm{p}<0.01$; Figure 2). Among infants surviving more than 3 days, $9482 / 29252$ (32\%) were diagnosed with lateonset sepsis, with the percent increasing with decreasing GA (28 weeks: 1396/7149 [20\%], 22 weeks: 122/200 [61\%]). From 1993 to 2004, the percent of infants with late-onset sepsis remained stable or increased slightly depending on GA (Figure 2, eTable 3). After 2004, the rate of late-onset sepsis decreased for infants of each GA (2005 to 2012, 24 weeks: 143/264 [54\%] to 89/225 [40\%], aRR: 0.94 [0.93-0.95]; 26 weeks: 109/296 [37\%] to 85/320 [27\%], aRR: 0.93 [0.92-0.94]; 28 weeks: 84/415 [20\%] to 34/418 [8\%], aRR: 0.91 [0.90-0.92]; eFigure 5).

The percent of infants with severe ICH decreased from 1993 to 2012 (Figure 2, eTable 3). The reduction was significant for infants born at $26(44 / 235$ [19\%] to 35/321 [11\%], 
$\mathrm{p}=0.03), 27$ (40/261 [15\%] to 25/349 [7\%], $\mathrm{p}=0.02)$, and 28 weeks (32/297 [11\%] to 21/417 [5\%], $\mathrm{p}<0.01$ ) but not for infants 22-25 weeks (eFigure 6). PVL decreased for infants born at 26-28 weeks GA (26 weeks, 15/194 [8\%] in 1993 to 13/322 [4\%] in 2012, aRR: 0.94 [0.92-0.96]; eTable 3, eFigure 7).

Of the 26,749 infants still hospitalized at 28 days, 24,991 (93\%) had an ophthalmologic examination prior to discharge. Retinopathy of prematurity was diagnosed for 15,022/24,987 $(60 \%)$ overall $(3,720 / 24,951$ [15\%] with stage 3 or higher), with an inverse relationship between diagnosis and GA (22 weeks: 101/113 [89\%], 47/113 [42\%] \tage 3; 28 weeks: $2156 / 6289$ [34\%], 171/6279 [3\%] $\triangle$ tage 3). Diagnosis of ROP decreased for infants born at 25-28 weeks, with limited or no change for infants born at 22-24 weeks (eTable 3). ROP stage 3 or higher increased from 124/941 (13\%) in 1993 to 262/1385 (19\%) in 2003, but decreased to 160/1509 (11\%) by 2012 (aRR for the change per year 2004-2012: 0.94 [0.930.95]; Figure 2).

The diagnosis of BPD rose from 295/911 (32\%) in 1993 to 547/1213 (45\%) in 2000 (aRR: 1.05 [1.04-1.06]), but decreased to 498/1230 (40\%) in 2008 (Figure 2). From 2009-2012, BPD rates increased for infants born at 26 weeks (130/258 [50\%] to 164/297 [55\%], p $<0.001)$ and 27 weeks $(103 / 312$ [33\%] to 134/339 [40\%], p=0.007), but not for infants 2225 or 28 weeks (eTable 3, eFigure 8). Among the 8 centers in the NRN all 20 years, BPD rates increased from 2009-2012 for all GAs except 28 weeks.

\section{Survival}

Survival increased with increasing GA (2012: 22 weeks, $7 / 75$ [9\%]; 28 weeks, 405/430 [94\%]; Table 3). Survival rates remained unchanged from 1993 through 2008. After 2008, trends in survival varied by GA (Figure 3). From 2009-2012, survival increased for infants born at 23 weeks (41/152 [27\%] to 50/150 [33\%], aRR for the change per year: 1.09 [1.051.14 ], $\mathrm{p}<0.001)$ and 24 weeks (156/248 [63\%] to 174/269 [65\%], aRR: 1.05 [1.03-1.07], $\mathrm{p}<0.001)$, with smaller relative increases for infants born at 25 weeks $(237 / 300$ [79\%] to 249/308 [81\%], aRR: 1.02 [1.01-1.03]) and 27 weeks (311/345 [90\%] to 337/357 [94\%], aRR: 1.01 [1.002-1.016]). Survival to discharge did not change significantly between 2009 and 2012 for infants born at 22, 26, and 28 weeks.

Among infants who survived to discharge, survival without major morbidity varied by GA (Table 3, Figure 4), with no significant change in the proportion of infants born at 22-24 weeks who survived to discharge without major morbidity. While 99/1550 (6\%) infants born at 22 weeks survived to discharge, only 5 survived without major morbidity. However, an increase of approximately $2 \%$ per year was seen for infants born at 25-28 weeks (Figure 4). By 2012, over half of infants born at 28 weeks who survived to discharge survived without major morbidity (1993: 88/207 [43\%], 2012: 230/387 [59\%], aRR: 1.03 [1.02-1.03], $\mathrm{p}<0.001$ ). Trends in survival and survival without major morbidity were similar in the 8 centers in the NRN all 20 years (eTable 4).

Survivors remained in hospital an average of 93 days [median (IQR): 85 days (66-109 days)], with median hospitalization varying with GA from 140 days for those born at 22 weeks to 63 days for infants born at 28 weeks. Median postmenstrual age at discharge 
decreased from 42 weeks for surviving infants born at 22 weeks GA to 37 weeks for those born at 28 weeks, $\mathrm{p}<0.001$.

\section{Discussion}

This study of extremely preterm infants born at NRN centers is the first comprehensive review to our knowledge to evaluate how care practices, major morbidities, and mortality have evolved over a 20 -year period. The study provides a global overview and level of detail not presented in earlier studies. Findings demonstrate that progress is being made and outcomes of the most immature infants are improving.

We demonstrated a significant increase in survival to discharge for infants born at 23-25 and 27 weeks, with the largest gains for those born at 23 and 24 weeks. Although methods differed, these findings are consistent with a recent study from the NRN on causes and timing of death among extremely preterm infants. ${ }^{22}$ In addition to increasing survival, an important goal of obstetrical and neonatal care is to reduce morbidities and improve neonatal outcome. Perhaps the most important new finding is a significant increase in survival without major neonatal morbidity for infants born at 25-28 weeks. Although overall survival increased for infants 23-24 weeks, few infants less than 25 weeks GA survived without major neonatal morbidity, underscoring the continued need for interventions to improve outcomes for the most immature infants.

At very early GAs, the decision to provide active obstetrical management and neonatal intensive care is complex and requires a team approach with discussions between the obstetrical and neonatal teams and the family. ${ }^{23-25}$ All infants in this study were delivered in academic centers with availability of tertiary maternal fetal medicine and comprehensive neonatal care. Changes in race/ethnicity likely reflect changes in the centers in the NRN over time and changes in populations served. About a quarter of infants were multiple births, with a significant increase over the study period, consistent with national trends and increased use of fertility treatments. ${ }^{26}$

An important finding is the increased adherence to care practices that have been associated with improved neonatal outcomes. Antenatal corticosteroids are one of the most effective interventions. ${ }^{27-31}$ The 1995 National Institutes of Health consensus statement on antenatal corticosteroids led to widespread use. Recent studies have documented benefits to infants as young as 22-23 weeks. Among our patients, antenatal steroid administration increased from only $24 \%$ in 1993 to $87 \%$ in 2012. We also found a changing pattern of antenatal antibiotic use and a significant increase in cesarean deliveries between 1993 and 2005, with increases noted for infants of each GA. Increased obstetrical interventions among the most immature infants, 22-24 weeks, suggests increased willingness to provide active management of pregnancies near the limit of viability.

Strategies to reduce lung injury, including less aggressive ventilation, are increasingly embraced. In our cohort, changes in respiratory care were documented with decreased intubation in the delivery room but increased surfactant use, suggesting an increase in selective use of surfactant. ${ }^{32}$ Avoidance of intubation in the delivery room might lead to 
increased surfactant use if early CPAP is insufficient to prevent alveolar collapse in some infants. There were modest increases in the percent of infants 24-28 weeks who were never ventilated. High frequency ventilation increased for infants at each GA, mainly between 2002 and 2007, and less invasive methods of ventilation (nasal SIMV, CPAP as highest level of support) increased overall. These trends are consistent with changes in care reported by other multicenter networks. ${ }^{4,7,33}$

Despite increased use of maternal antibiotics over the years, rates of early-onset sepsis did not change significantly. Earlier NRN studies among extremely preterm infants reported a substantial reduction in early-onset Group B Streptococcal sepsis with a concomitant increase in early-onset $E$. coli sepsis ${ }^{18,34}$. By contrast, we documented a substantial reduction in late-onset sepsis from 2005 to 2012 for infants of each GA. Although we did not collect information on infection control practices, the reduction in late-onset sepsis likely reflects increased attention to improved hand hygiene, skin care, human milk feeding, uniform practices for catheter insertion and care (central line bundles), and attention to discontinuing invasive devices when not needed. ${ }^{35-38}$ Given earlier studies linking infection to increased risk of impairment, decreased rates of late-onset sepsis may contribute to improved long-term outcomes for extremely preterm infants ${ }^{39}$. Rates of ROP decreased for infants born at 25-28 weeks and may be related to changes in oxygen use in the delivery room and oxygen saturation targets or to improved adherence to oxygen targets at NRN hospitals during and since the SUPPORT trial (2005-2009) ${ }^{40}$.

Among infants who survived to 36 weeks postmenstrual age, BPD rates increased from 2009-2012 for infants born at 26 and 27 weeks, with significant increases for infants 22-27 weeks born in the 8 centers in the NRN all 20 years. This may partly be explained by increased active resuscitation and intensive care and increased survival, especially for the most immature infants. The effect of decreased intubation/ventilation and decreased postnatal corticosteroid use in our population is unclear, although recent meta-analyses suggest that increased early CPAP with reduced intubation/ventilation has a modest effect in reducing $\mathrm{BPD}^{41}$, while decreased use of postnatal steroids increases BPD risk ${ }^{42}$.

Strengths of this study are the large number of infants and the rigorous prospective data collection. However, the study has several limitations. The NRN cohort is hospital-based rather than population-based. Although large, our cohort is not representative of the entire US preterm population, but rather a selected preterm population from academic centers. Although infants who died within 12 hours were included in the analyses of survival, we collected limited information on these infants and thus could not include them in analyses of morbidities. Although the registry's manual of operations provides detailed definitions, we were unable to evaluate potential diagnostic variabilities across sites (e.g., differences in reading cranial ultrasounds or interpreting ophthalmologic examinations). We presented epidemiologic associations and changes over time, but registry data and the cohort design do not provide definitive reasons for the changes observed.

Although the NRN conducts developmental follow-up on a subset of infants included in the registry, follow-up data are not included in this study. We reported only modest declines in severe ICH and PVL, early markers of brain injury. Given the long-term goal of intact 
survival and a healthy neurodevelopmental trajectory, it is critical to develop neuroprotective and neuro-promoting "brain care bundles," similar to infection reduction approaches. Attention to optimal nutrition, limitation of invasive procedures, pain management, infection control practices, and reduction of other inflammatory conditions may also promote healthy neurodevelopment.

Despite improvements in survival, medical science may have reached the limits of what current technologies can provide. On-going studies are addressing whether sequencing the genome can provide useful information beyond current newborn screening to accelerate diagnoses and improve care. Other novel areas that warrant further study include advanced brain imaging to better understand injury, repair and growth; minimally invasive delivery of aerosolized surfactant; tissue engineering and regenerative medicine; and selected growth factors and cellular therapies.

Although survival of extremely preterm infants has increased over the past 2 decades, including survival without major morbidity, the individual and societal burden of preterm birth remains substantial, ${ }^{43}$ with approximately 450,000 neonates born prematurely in the United States each year. ${ }^{44}$ To truly impact newborn outcomes, a comprehensive and sustained effort to reduce the high rates of preterm birth is necessary.

\section{Conclusions}

Among extremely preterm infants born at US academic centers over the last 20 years, changes in maternal and infant care practices and modest reductions in several morbidities were observed, although bronchopulmonary dysplasia increased. Survival increased most markedly for infants born at 23 and 24 weeks and survival without major morbidity increased for infants $25-28$ weeks. These findings are valuable in counselling families and developing novel interventions.

\section{Supplementary Material}

Refer to Web version on PubMed Central for supplementary material.

\section{Acknowledgments}

The National Institutes of Health, the Eunice Kennedy Shriver National Institute of Child Health and Human Development (NICHD), the National Center for Research Resources, and the National Center for Advancing Translational Sciences provided grant support for the Neonatal Research Network's Generic Database Study to maintain a high risk preterm infant registry through cooperative agreements.

Role of Sponsor: NICHD staff had input into the design and conduct of the study; collection, management, analysis, and interpretation of the data; preparation, review, or approval of the manuscript; and decision to submit the manuscript for publication.

\section{References}

1. Fanaroff AA, Stoll BJ, Wright LL, et al. Trends in neonatal morbidity and mortality for very low birthweight infants. Am J Obstet Gynecol. 2007; 196:147.e1-8. [PubMed: 17306659]

2. Stoll BJ, Hansen NI, Bell EF, et al. for the NICHD Neonatal Research Network. Neonatal outcomes of extremely preterm infants from the NICHD Neonatal Research Network. Pediatrics. 2010; 126:443-456. [PubMed: 20732945] 
3. Horbar JD, Carpenter JH, Badger GJ, et al. Mortality and neonatal morbidity among infants 501 to 1500 grams from 2000 to 2009. Pediatrics. 2012; 129:1019-1026. [PubMed: 22614775]

4. Shah PS, Sankaran K, Aziz K, et al. the Canadian Neonatal Network. Outcomes of preterm infants $<29$ weeks gestation over 10-year period in Canada: a cause for concern? J Perinatol. 2012; 32:132138. [PubMed: 21593814]

5. Berger TM, Steurer MA, Woerner A, et al. for the Swiss Neonatal Network. Trends and centre-tocentre variability in survival rates of very preterm infants ( $<32$ weeks) over a 10 -year period in Switzerland. Arch Dis Child Fetal Neonatal Ed. 2012; 97:F323-F328. [PubMed: 22933089]

6. Ancel P-Y, Goffinet F, the EPIPAGE-2 Writing Group. Survival and morbidity of preterm children born at 22 through 34 weeks' gestation in France in 2011: results of the EPIPAGE-2 Cohort study. JAMA Pediatr. 2015; 169:230-238. [PubMed: 25621457]

7. Grisaru-Granovsky S, Reichman B, Lerner-Geva L, et al. the Israel Neonatal Network. Populationbased trends in mortality and neonatal morbidities among singleton, very preterm, very low birth weight infants over 16 years. Early Hum Dev. 2014; 90:821-827. [PubMed: 25463827]

8. Institute of Medicine (US) Committee on Understanding Premature Birth and Assuring Healthy Outcomes. Behrman, RE.; Butler, AS., editors. Preterm Birth: Causes, Consequences, and Prevention. Washington (DC): National Academies Press (US); 2007.

9. Saigal S, Doyle LW. An overview of mortality and sequelae of preterm birth from infancy to adulthood. Lancet. 2008; 371:261-269. [PubMed: 18207020]

10. Hack M, Horbar JD, Malloy MH, Tyson JE, Wright E, Wright L. Very low birth weight outcomes of the National Institute of Child Health and Human Development Neonatal Network. Pediatrics. 1991; 87:587-597. [PubMed: 2020502]

11. Alexander GR, Himes JH, Kaufman RB, Mor J, Kogan M. A United States national reference for fetal growth. Obstet Gynecol. 1996; 87:163-168. [PubMed: 8559516]

12. Hack M, Wright LL, Shankaran S, et al. Very-low-birth-weight outcomes of the National Institute of Child Health and Human Development Neonatal Network, November 1989 to October 1990. Am J Obstet Gynecol. 1995; 172:457-464. [PubMed: 7856670]

13. Fanaroff AA, Wright LL, Stevenson DK, et al. Very-low-birth-weight outcomes of the National Institute of Child Health and Human Development Neonatal Research Network, May 1991December 1992. Am J Obstet Gynecol. 1995; 173:1423-1431. [PubMed: 7503180]

14. Stevenson DK, Wright LL, Lemons JA, et al. Very-low-birth-weight outcomes of the NICHD Neonatal Research Network, January 1993 through December 1994. Am J Obstet Gynecol. 1998; 179:1632-1639. [PubMed: 9855609]

15. Lemons JA, Bauer CR, Oh W, et al. Very-low-birth-weight outcomes of the NICHD Neonatal Research Network, January 1995 through December 1996. Pediatrics. 2001; 107:e1. [PubMed: 11134465]

16. Bell MJ, Ternberg JL, Feigin RD, et al. Neonatal necrotizing enterocolitis: Therapeutic decisions based upon clinical staging. Ann Surg. 1978; 187:1-7. [PubMed: 413500]

17. Walsh MC, Kliegman RM. Necrotizing enterocolitis: treatment based on staging criteria. Pediatr Clin North Am. 1986; 33:179-201. [PubMed: 3081865]

18. Stoll BJ, Hansen NI, Sánchez PJ, et al. Early onset neonatal sepsis: The burden of group B streptococcal and E. coli disease continues. Pediatrics. 2011; 127:817-826. [PubMed: 21518717]

19. Stoll BJ, Hansen N, Fanaroff AA, et al. Late-onset sepsis in VLBW neonates: The experience of the NICHD Neonatal Research Network. Pediatrics. 2002; 110:285-291. [PubMed: 12165580]

20. Papile LA, Burstein J, Burstein R, Koffler H. Incidence and evolution of subependymal and intraventricular hemorrhage: a study of infants with birth weights less than 1,500 gm. J Pediatr. 1978; 92:529-534. [PubMed: 305471]

21. Zou G. A modified Poisson regression approach to prospective studies with binary data. Am J Epidemiol. 2004; 159:702-706. [PubMed: 15033648]

22. Patel RM, Kandefer S, Walsh MC, et al. for the NICHD Neonatal Research Network. Causes and timing of death in extremely premature infants from 2000 through 2011. N Engl J Med. 2015; 372:331-340. [PubMed: 25607427]

23. Raju TN. Periviable birth: executive summary of a joint workshop by the Eunice Kennedy Shriver National Institute of Child Health and Human Development, Society for Maternal Fetal Medicine, 
American Academy of Pediatrics, and American College of Obstetricians and Gynecologists. Am J Obstet Gynecol. 2014; 210:406-417. [PubMed: 24725732]

24. Guinsburg R, Branco de Almeida MF, dos Santos Rodrigues Sadeck L, et al. for the Brazilian Network on Neonatal Research. Proactive management of extreme prematurity: disagreement between obstetricians and neonatologists. J Perinatol. 2012; 32:913-919. [PubMed: 22460546]

25. Tyson JE, Stoll BJ. Evidence-based ethics and the care and outcome of extremely premature infants. Clin Perinatol. 2003; 30:363-387. [PubMed: 12875360]

26. Kulkarni AD, Jamieson DJ, Jones HW, et al. Fertility treatments and multiple births in the United States. N Engl J Med. 2013; 369:2218-2225. [PubMed: 24304051]

27. NIH. Consensus Development Panel on the Effect of Corticosteroids for Fetal Maturation on Perinatal Outcomes. JAMA. 1995; 273:413-418. [PubMed: 7823388]

28. Carlo WA, McDonald SA, Fanaroff AA, et al. for the NICHD Neonatal Research Network. Association of antenatal corticosteroids with mortality and neurodevelopmental outcomes among infants born at 22 to 25 weeks' gestation. JAMA. 2011; 306:2348-2358. [PubMed: 22147379]

29. Mori R, Kusuda S, Fujimura M. Antenatal corticosteroids promote survival of extremely preterm infants born at 22 to 23 weeks of gestation. J Pediatr. 2011; 159:110-114. [PubMed: 21334006]

30. Malloy MH. Antenatal steroid use and neonatal outcome: United States 2007. J Perinatol. 2012; 32:722-727. [PubMed: 22441114]

31. Wong D, Abdel-Latif ME, Kent AL, for the NICUS Network. Antenatal steroid exposure and outcomes of very premature infants: a regional cohort study. Arch Dis Child Fetal Neonatal. 2014; (99):F12-F20.

32. Rojas-Reyes MX, Morley CJ, Soll R. Prophylactic versus selective use of surfactant in preventing morbidity and mortality in preterm infants. Cochrane Database Syst Rev. 2012(3):CD000510. [PubMed: 22419276]

33. Soll RF, Edwards EM, Badger GJ, et al. Obstetric and neonatal care practices for infants 501 to $1500 \mathrm{~g}$ from 2000 to 2009. Pediatrics. 2013; 132:222-228. [PubMed: 23858426]

34. Stoll BJ, Hansen N, Fanaroff AA, et al. Changes in pathogens causing early-onset sepsis in verylow-birth-weight infants. N Engl J Med. 2002; 347:240-247. [PubMed: 12140299]

35. Shane AL, Stoll BJ. Neonatal sepsis: progress towards improved outcomes. J Infect. 2014; 68:S24S32. [PubMed: 24140138]

36. Schulman J, Stricof R, Stevens TP, et al. Statewide NICU central-line-associated bloodstream infection rates decline after bundles and checklists. Pediatrics. 2011; 127:436-444. [PubMed: 21339265]

37. Wirtschafter DD, Powers RJ, Pettit JS, et al. Nosocomial infection reduction in VLBW infants with a statewide quality-improvement model. Pediatrics. 2011; 127:419-426. [PubMed: 21339273]

38. Kaplan HC, Lannon C, Walsh MC, et al. Ohio statewide quality-improvement collaborative to reduce late-onset sepsis in preterm infants. Pediatrics. 2011; 127:427-435. [PubMed: 21339274]

39. Stoll BJ, Hansen NI, Adams-Chapman, et al. for the National Institute of Child Health and Human Development Neonatal Research Network. Neurodevelopmental and growth impairment among extremely low-birth-weight infants with neonatal infection. JAMA. 2004; 292:2357-2365. [PubMed: 15547163]

40. Carlo WA, Finer NN, Walsh MC, et al. for the NICHD Neonatal Research Network and the SUPPORT Study Group. Target ranges of oxygen saturation in extremely preterm infants. N Engl J Med. 2010; 362:1959-1969. [PubMed: 20472937]

41. Schmolzer GM, Kumar M, Pichler G, et al. Non-invasive versus invasive respiratory support in preterm infants at birth: systemic review and meta-analysis. BMJ. 2013; 347:f5980. [PubMed: 24136633]

42. Doyle LW, Ehrenkranz RA, Halliday HL. Late (>7 days) postnatal corticosteroids for chronic lung disease in preterm infants. Cochrane Database of Systemic Reviews. 2014; (5) Art No.: CD001145. 10.1002/14651858.CD001145.pub3

43. McCabe ERB, Carrino GE, Russell RB, Howse JL. Fighting for the next generation: US prematurity in 2030. Pediatrics. 2014; 134:1193-1199. [PubMed: 25367536] 
44. Martin, JA.; Hamilton, BE.; Osterman, MJK., et al. National vital statistics reports. Vol. 64. Hyattsville, MD: National Center for Health Statistics; 2015. Births: Final data for 2013. http:// www.cdc.gov/nchs/data/nvsr/nvsr64/nvsr64_01.pdf 


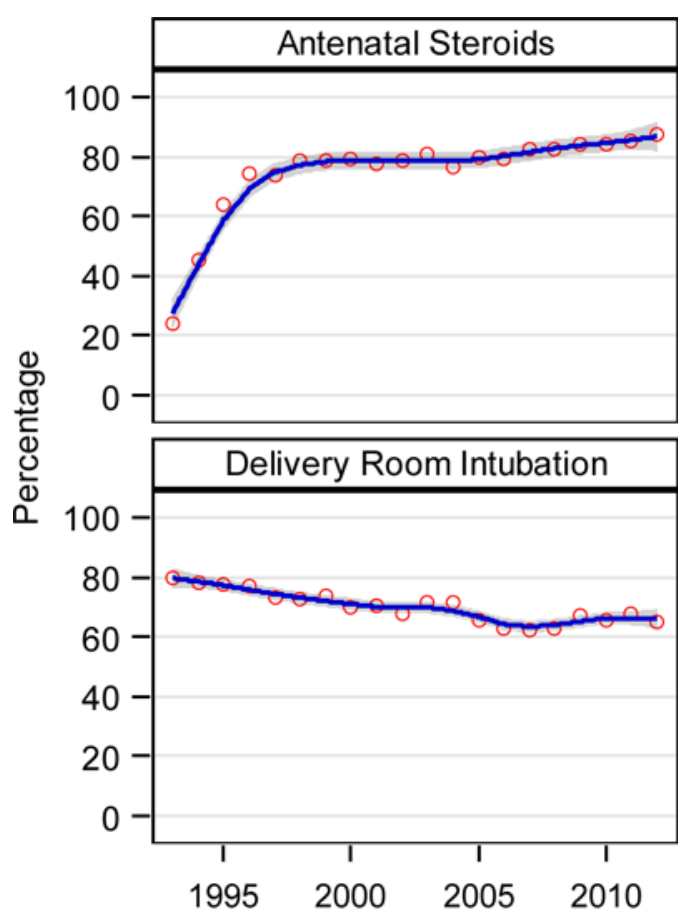

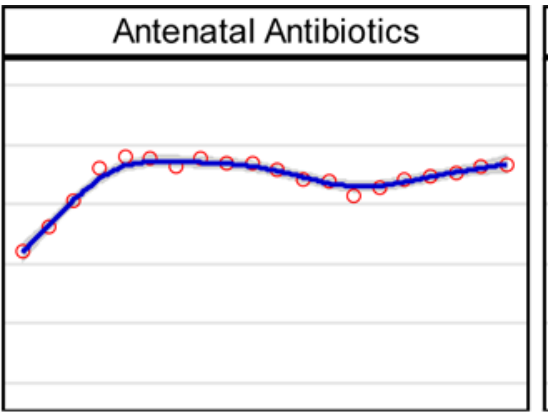

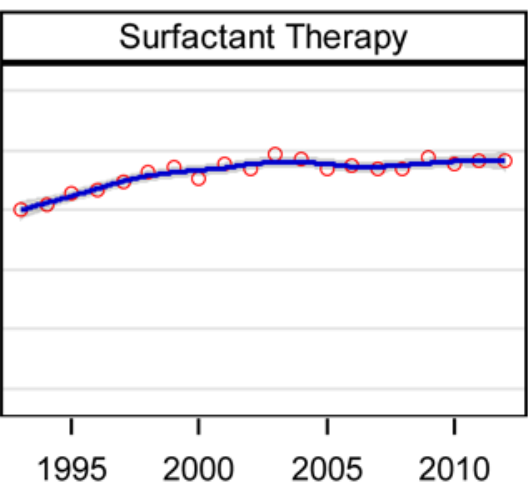

Birth Year
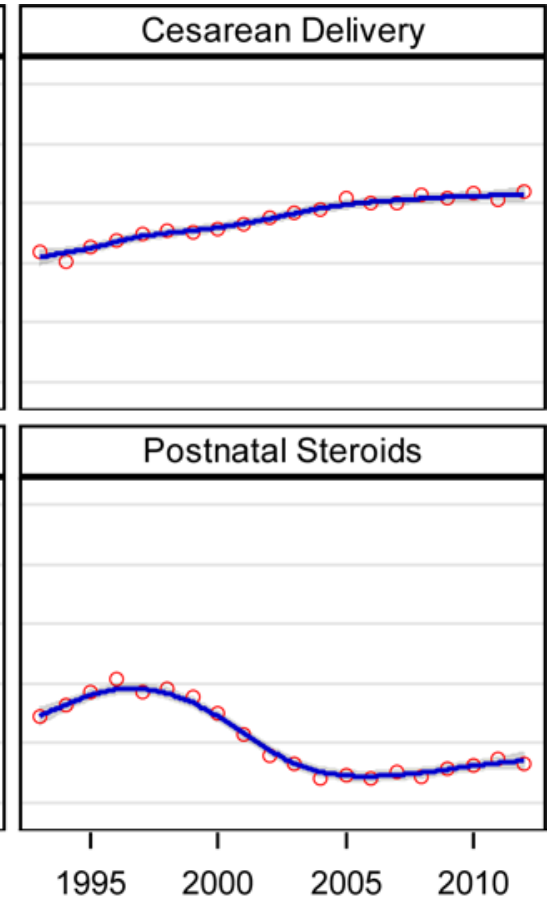

Figure 1.

Care practices by birth year for infants born at GA 22-28 weeks 1993-2012. In each graph, circles show the percent of infants born each year who received the practice, a smoothed curve shows the trend, and shading indicates a 95\% CI for the curve. Shading is not visible where CIs are close to values on the curve. Percents are among all infants, except that for postnatal steroids percents are among infants who survived $>12$ hours as this outcome was not collected for infants who died $\leq 12$ hours of age. Relative risks based on infants of all GA 22-28 weeks are shown for outcomes for which the year-GA interaction was not significant. When the year-GA interaction was significant, graphs and relative risks are shown for each GA in eFigures 1-4. Relative risks for the change per year were adjusted for study center, maternal race/ethnicity, infant GA, SGA, and sex. Total number of infants included [mean (range) per year] in each graph were: antenatal steroids, 34576 [1728 (12142022)]; antenatal antibiotics, 34531 [1726 (1210-2020)]; cesarean delivery, 34611 [1730 (1213-2024)]; intubation, 34611 [1730 (1214-2024)]; surfactant, 34599 [1729 (12142023)]; postnatal steroids, 30645 [1532 (1036-1802)].

\begin{tabular}{ccc} 
Adjusted RR $(95 \% \mathrm{CI})$ for the change per year in all infants where year-GA interaction non-significant \\
\hline Antenatal Steroids & Antenatal Antibiotics & Cesarean Delivery \\
\hline
\end{tabular}

1993-1997: $1.14(1.12-1.15)$

(see eFigure 1) 1998-2006: $0.978(0.976-0.981) \quad$ (see eFigure 2)

2007-2012: 1.019 (1.014-1.023)

\begin{tabular}{lcc}
\hline Delivery Room Intubation & Surfactant Therapy & Postnatal Steroids \\
\hline & $1993-1996: 1.18(1.14-1.21)$
\end{tabular}



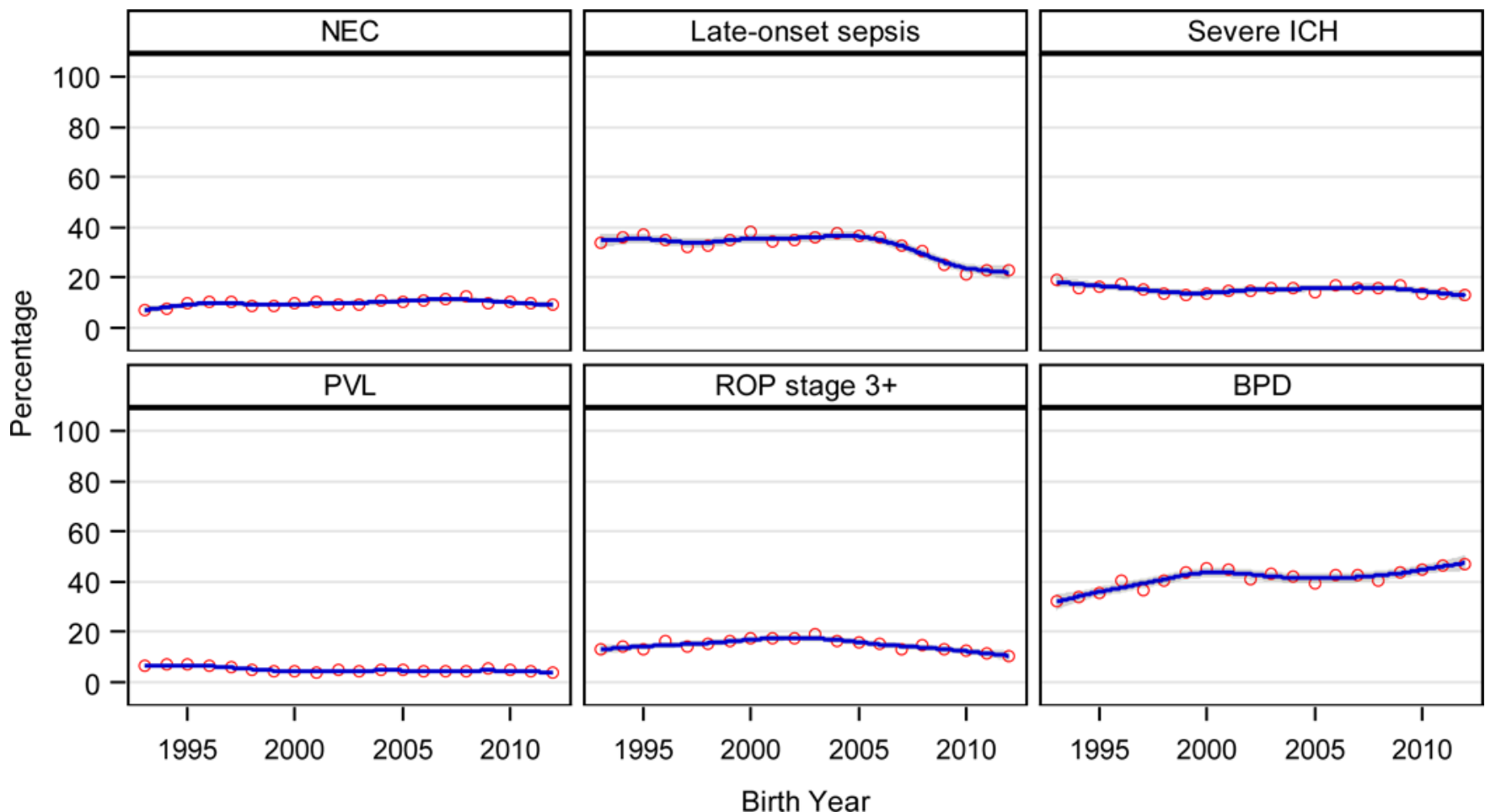

Figure 2.

Neonatal morbidities by birth year for infants born at GA 22-28 weeks 1993-2012. In each graph, circles show the percent of infants born each year diagnosed with the morbidity and a smoothed curve shows the trend. Shading to indicate a 95\% CI for each curve is not visible where CIs are close to values on the curve. Percents shown in graphs are among infants of all GA who survived $>12$ hours with additional restrictions as noted in text and eTable 3 . Relative risks based on infants of all GA 22-28 weeks are shown for outcomes for which the year-GA interaction was not significant. When the year-GA interaction was significant, graphs and relative risks are shown for each GA in eFigures 5-8. Relative risks for the change per year were adjusted for study center, maternal race/ethnicity, infant GA, SGA, and sex. Total number of infants included [mean (range) per year] in each graph were: NEC, 30790 [1539 (1035-1809)]; late-onset sepsis, 29252 [1462 (980-1702)]; ICH, 29883 [1494 (1016-1741)]; PVL, 28498 [1424 (769-1744)]; ROP, 24951 [1247 (808-1509)]; BPD, 25000 [1250 (746-1534)].

\begin{tabular}{ccc}
\multicolumn{1}{c}{ Adjusted RR (95\% CI) for the change per year in all infants where year-GA interaction non-significant } \\
NEC & \multicolumn{1}{c}{ Late-onset sepsis } & Severe ICH \\
\hline $\begin{array}{c}\text { 1993-2008: 1.02 (1.01-1.03) } \\
\text { 2009-2012: 0.94 (0.91-0.98) }\end{array}$ & (see eFigure 5) & BPD \\
\hline PVL & ROP stage 3+ & \\
(see eFigure 7) & 1993-2003: 1.02 (1.01-1.03) & (see eFigure 8) \\
\hline
\end{tabular}



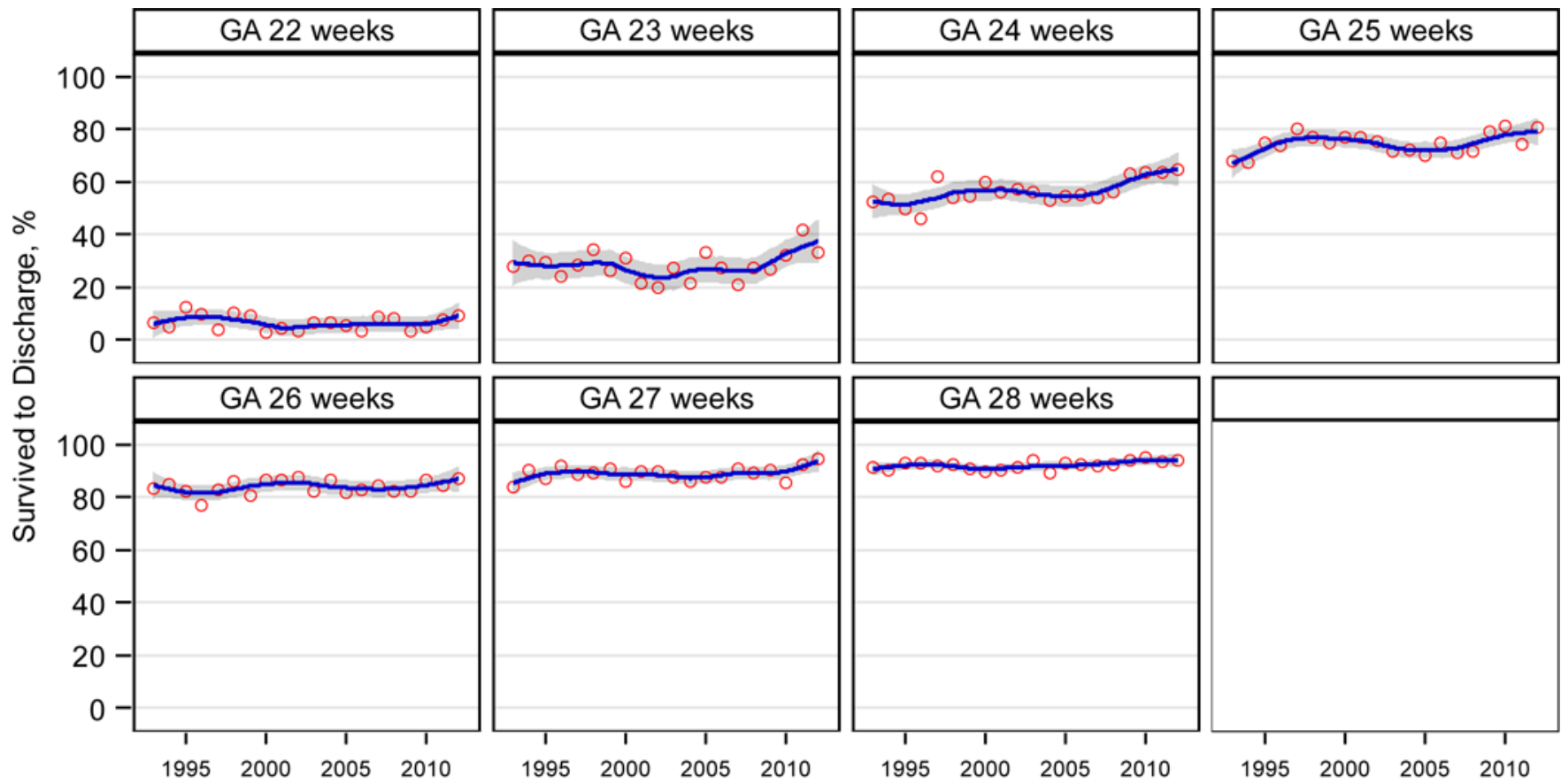

Birth Year

Figure 3.

Survival to discharge by birth year and GA among infants born 1993-2012. In each graph, circles show the percent of infants born each year who survived to discharge, a smoothed curve shows the trend, and shading indicates a 95\% CI for the curve. Shading is not visible where CIs are close to values on the curve. Percents are among all infants, including those who died $\leq 12$ hours. Relative risks for the change per year were adjusted for study center, maternal race/ethnicity, infant GA, SGA, and sex. Survival trends did not vary significantly by GA from 1993-2008 (year-GA interaction, $\mathrm{p}=0.46$ ) with no significant change in survival ( $p=0.90$ ) but varied by GA from 2009-2012 (year-GA interaction, $p<0.001$ ). Therefore, relative risks are shown for 2009-2012 only. Total number of infants included [mean (range) per year] in each graph were: 22 weeks, 1550 [77 (48-96)]; 23 weeks, 3133 [156 (122-189)]; 24 weeks, 4762 [238 (151-334)]; 25 weeks, 5361 [268 (170-339)]; 26 weeks, 5829 [291 (182-361)]; 27 weeks, 6627 [331(204-399)]; 28 weeks, 7374 [368 (275430)].

\begin{tabular}{cccc}
\hline \multicolumn{4}{c}{ Adjusted RR $(95 \%$ CI $)$ for the change per year 2009-2012 } \\
\hline 22 weeks & 23 weeks & 24 weeks & 25 weeks \\
\hline $1.06(0.89-1.25)$ & $1.09(1.05-1.14)$ & $1.05(1.03-1.07)$ & $1.02(1.01-1.03)$ \\
\hline 26 weeks & 27 weeks & 28 weeks \\
\hline $1.00(0.996-1.015)$ & $1.01(1.002-1.016)$ & $1.00(0.998-1.011)$ \\
\hline
\end{tabular}



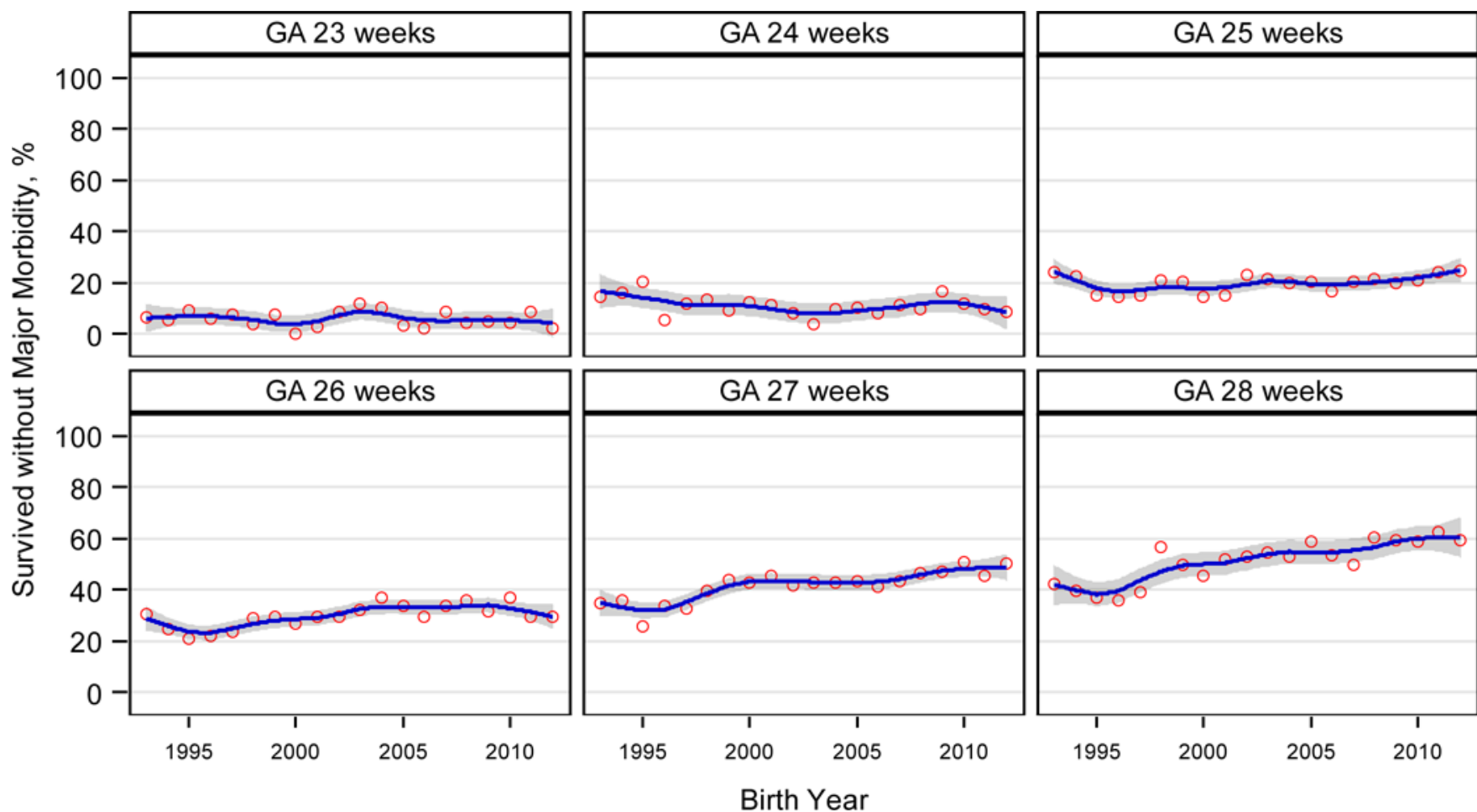

Birth Year

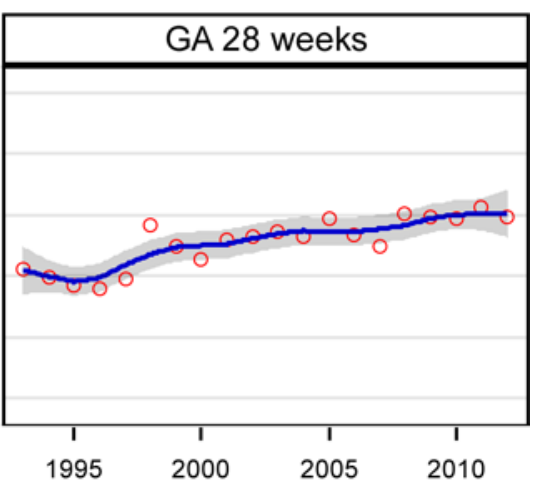

Figure 4.

Survival to discharge without major morbidity among infants who survived to discharge by birth year and GA among infants born 1993-2012. Major morbidity was defined as one or more of necrotizing enterocolitis, infections (early-onset sepsis, late-onset sepsis, or meningitis), BPD, severe ICH, PVL, and ROP stage 23 . In each graph, circles show the percent of infants who survived without major morbidity each year, a smoothed curve shows the trend, and shading indicates a 95\% CI for the curve. Percents are among infants who survived to discharge excluding those not adequately evaluated for major morbidity. Infants born at GA 22 weeks are not shown as only 99 of 1550 survived to discharge and only 5 survived without major morbidity. Relative risks for the change per year were adjusted for study center, maternal race/ethnicity, infant GA, SGA, and sex. Trends varied by GA (yearGA interaction $\mathrm{p}=0.01$ ). Total number of infants included [mean (range) per year] in each graph were: 23 weeks, 877 [43 (33-69)]; 24 weeks, 2706 [135 (75-183)]; 25 weeks, 4007 [200 (119-249)]; 26 weeks, 4900 [245 (155-313)]; 27 weeks, 5902 [295 (184-350)]; 28 weeks, 6808 [340 (256-405)].

\begin{tabular}{ccc}
\hline \multicolumn{3}{c}{ Adjusted RR $(95 \%$ CI) for the change per year } \\
\hline 23 weeks & 24 weeks & 25 weeks \\
\hline $1.00(0.95-1.05)$ & $0.99(0.97-1.01)$ & $1.02(1.01-1.03)$ \\
\hline 26 weeks & 27 weeks & 28 weeks \\
\hline $1.02(1.01-1.03)$ & $1.02(1.02-1.03)$ & $1.03(1.02-1.03)$ \\
\hline
\end{tabular}




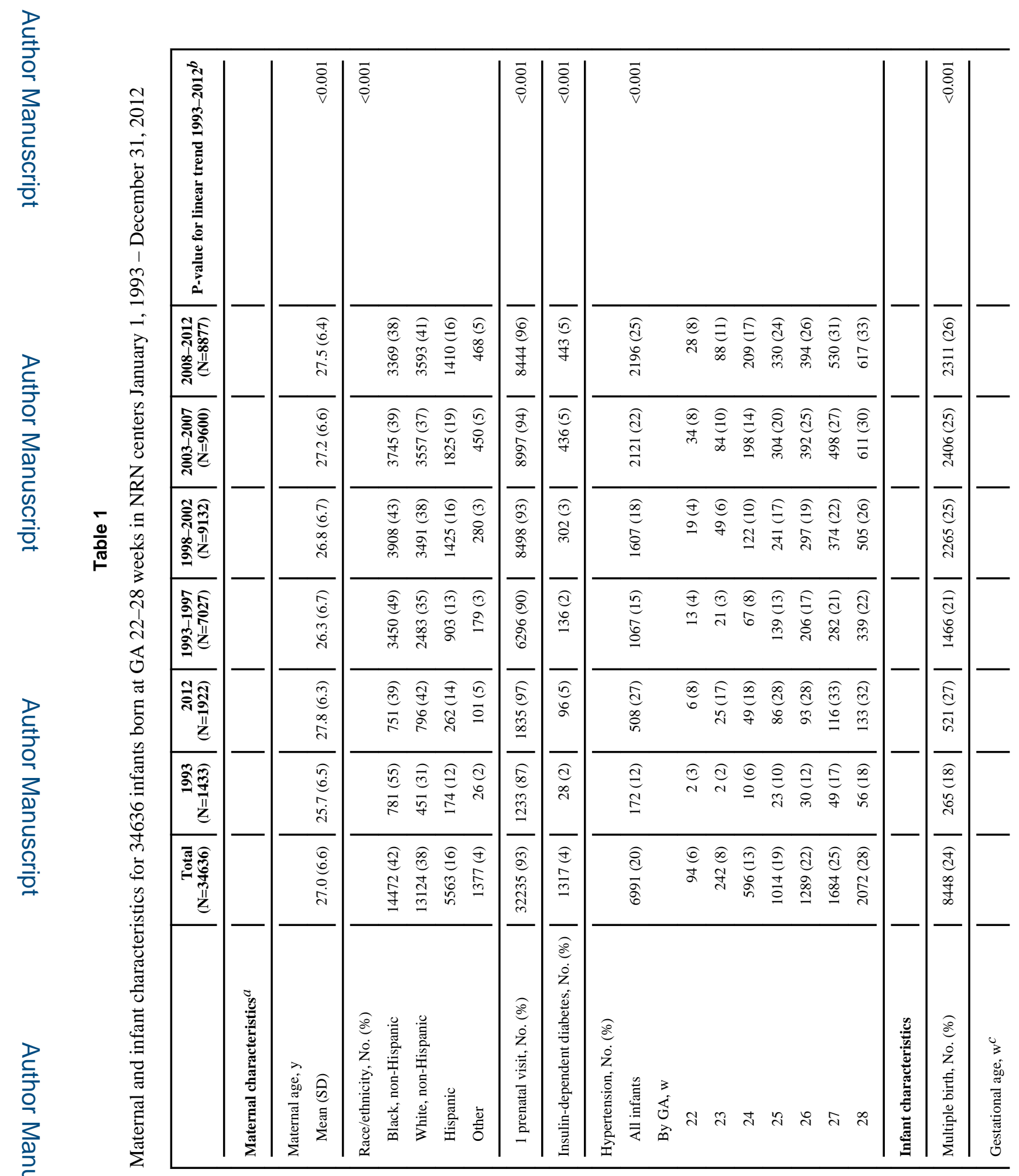

JAMA. Author manuscript; available in PMC 2016 March 11. 

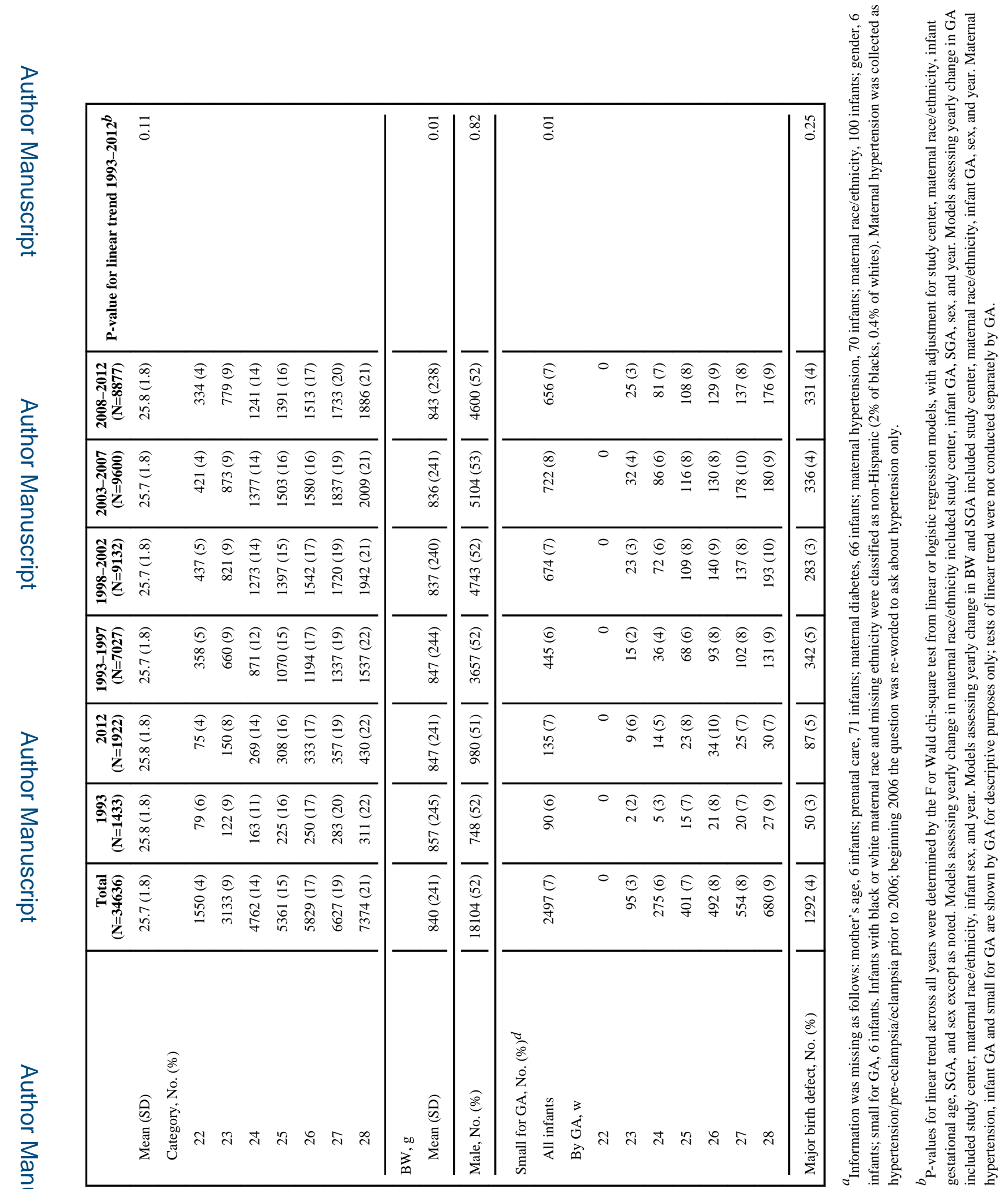

JAMA. Author manuscript; available in PMC 2016 March 11. 


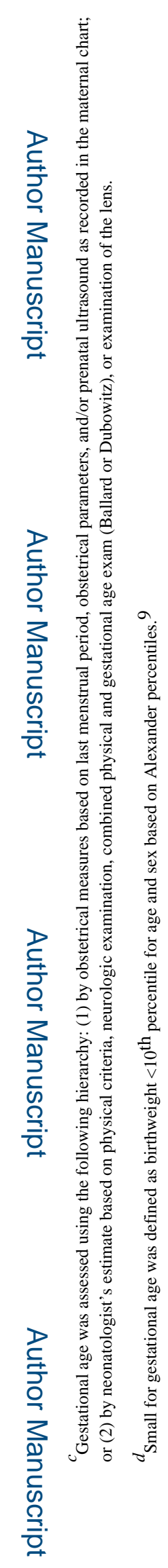

JAMA. Author manuscript; available in PMC 2016 March 11. 
Table 2

Respiratory support for 18246 infants born at GA 22-28 weeks in NRN centers January 1, 2002 - December 31, 2012 who survived $>12$ hours after birth ${ }^{a}$

\begin{tabular}{|c|c|c|c|c|}
\hline No. $(\%)$ & $\begin{array}{r}2002 \\
(\mathrm{~N}=1666)\end{array}$ & $\begin{array}{r}2012 \\
(\mathrm{~N}=1756)\end{array}$ & $\begin{array}{r}2003-2007 \\
(\mathrm{~N}=8546)\end{array}$ & $\begin{array}{r}2008-2012 \\
(\mathrm{~N}=8034)\end{array}$ \\
\hline Never used conventional or high-frequency ventilation & $167(10)$ & $255(15)$ & $886(10)$ & $1047(13)$ \\
\hline Any high-frequency ventilation & $504(30)$ & $632(36)$ & $3123(37)$ & $3070(38)$ \\
\hline Any conventional ventilation & $1497(90)$ & $1442(82)$ & $7446(87)$ & $6653(83)$ \\
\hline Any nasal SIMV & $239(14)$ & $657(37)$ & $1510(18)$ & $2592(32)$ \\
\hline Any CPAP therapy & $1314(79)$ & $1357(77)$ & $6680(78)$ & $6227(78)$ \\
\hline Nasal SIMV highest $b$ & $13(<1)$ & $45(3)$ & $89(1)$ & $178(2)$ \\
\hline CPAP highest $b$ & $120(7)$ & $190(11)$ & $663(8)$ & $746(9)$ \\
\hline
\end{tabular}

Information was missing as follows: never used conventional or high-frequency ventilation, 6 infants; high-frequency ventilation, 9 infants; conventional ventilation, 6 infants; any nasal SIMV, 11 infants; any CPAP, 13 infants; nasal SIMV highest, 6 infants; CPAP highest, 6 infants.

${ }^{a}$ Respiratory support outcomes were examined for infants born 2002-2012 due to changes in data collection. Analyses were repeated in the subset of 11 centers in the NRN all years 2002-2012 ( $\mathrm{N}=12,879)$.

${ }^{b}$ Highest level of support was defined for nasal SIMV as never used conventional or high-frequency ventilation but used nasal SIMV, and for CPAP as never used conventional or high-frequency ventilation or nasal SIMV but received CPAP therapy. 


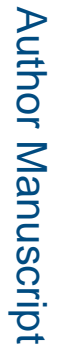

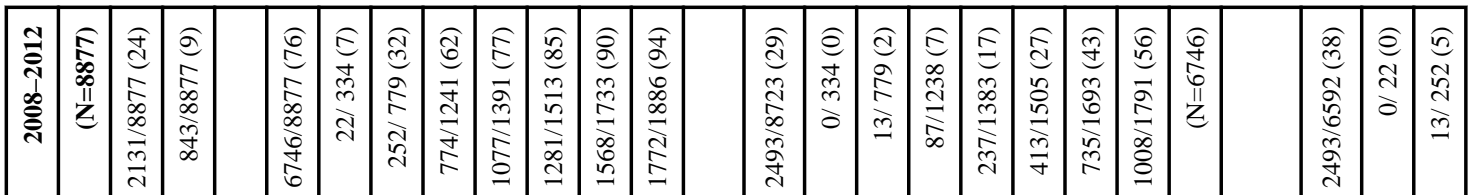

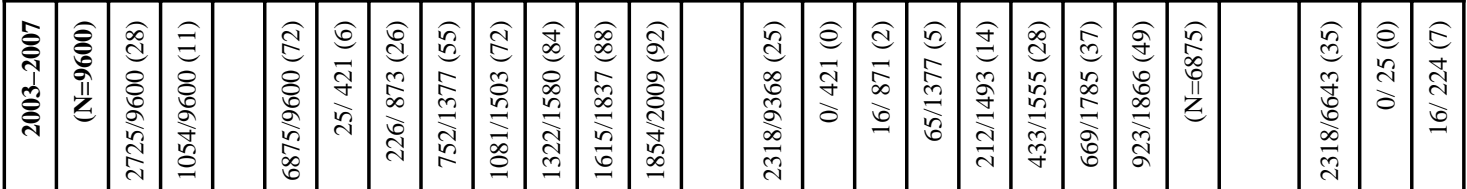

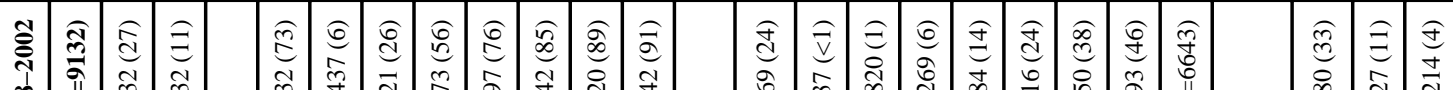

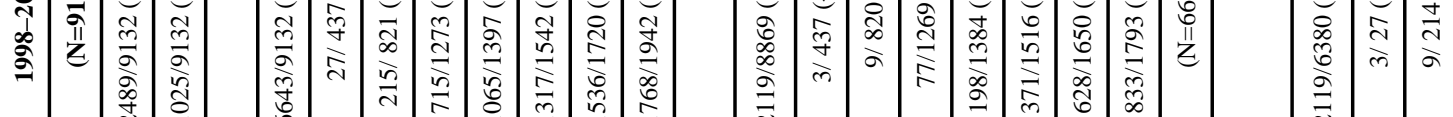

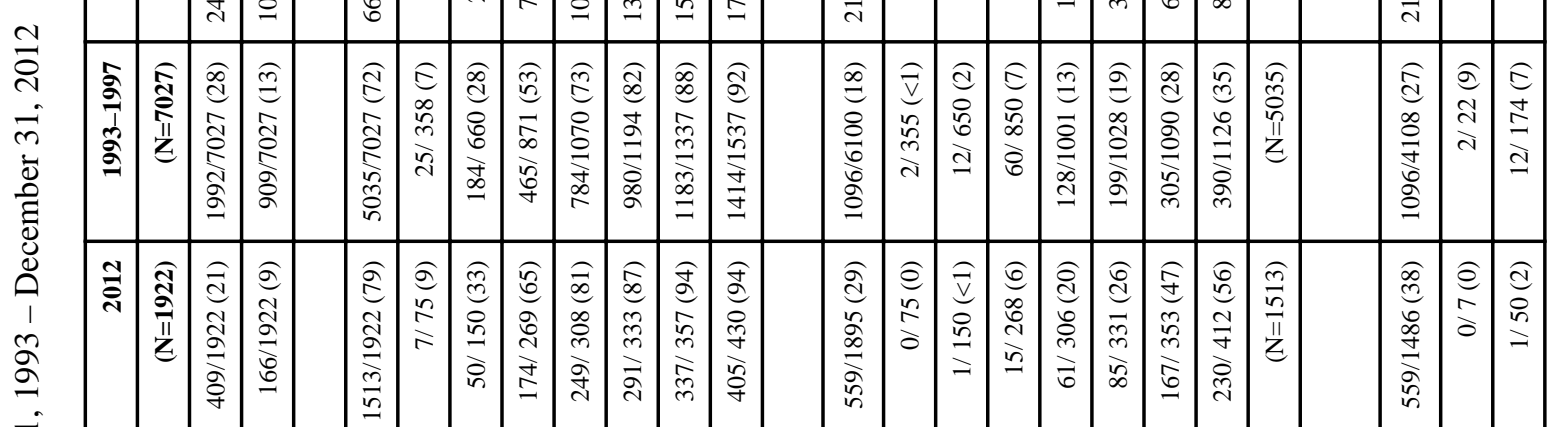

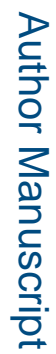

$$
\text { एँ }
$$

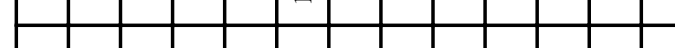

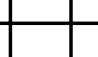

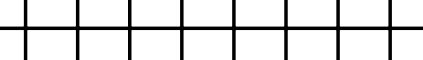

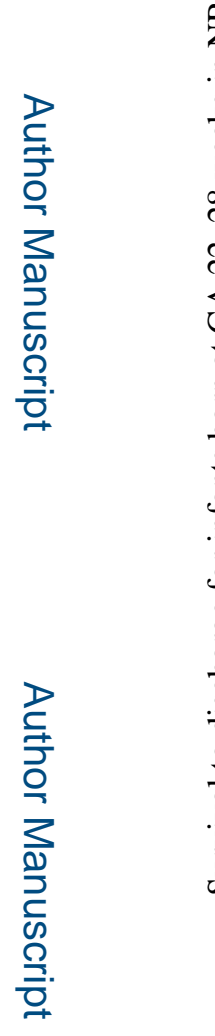

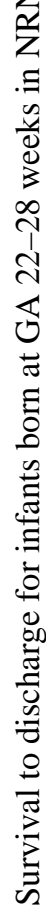

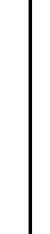

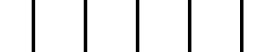




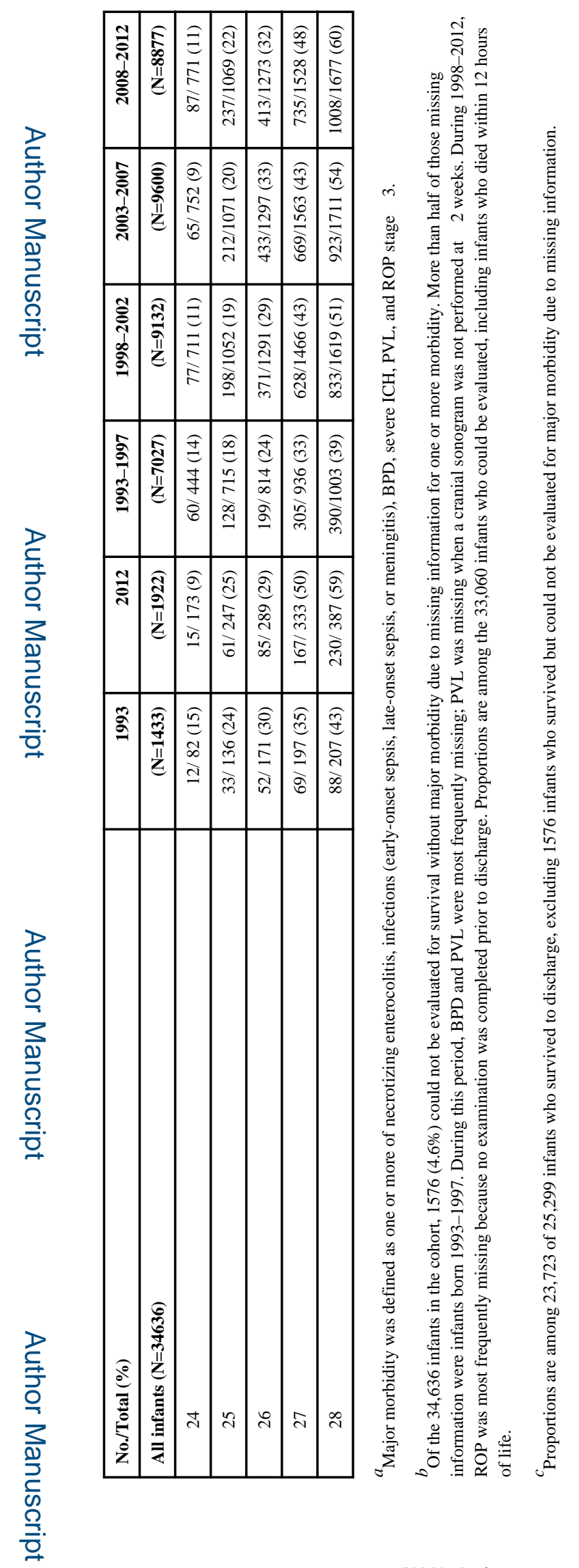

JAMA. Author manuscript; available in PMC 2016 March 11. 